\title{
Analysis of the Influence of Upper Protective Layer Mining on the Effect of Pressure Relief and Protection of Coal and Rock Masses between the Lower Overburden Layers
}

\author{
Jiaxin Dang $\mathbb{D}^{1,2}$ Min Tu $\mathbb{D}^{1,2}$, Xiangyang Zhang $\mathbb{D}$, ${ }^{1,2}$ and Qingwei Bu $\mathbb{D}^{1,3}$ \\ ${ }^{1}$ Key Laboratory of Coal Mine Safety and Efficiently Caving of Ministry of Education, \\ Anhui University of Science and Technology, Huainan 232001, China \\ ${ }^{2}$ School of Mining Engineering, Anhui University of Science and Technology, Huainan 232001, China \\ ${ }^{3}$ School of Mining and Coal, Inner Mongolia University of Science and Technology, Baotou 014010, China \\ Correspondence should be addressed to Min Tu; mtu@aust.edu.cn
}

Received 26 September 2021; Accepted 12 October 2021; Published 31 October 2021

Academic Editor: Ruimin Feng

Copyright (C) 2021 Jiaxin Dang et al. This is an open access article distributed under the Creative Commons Attribution License, which permits unrestricted use, distribution, and reproduction in any medium, provided the original work is properly cited.

\begin{abstract}
Protective seam mining is an effective gas pressure relief method in deep mining. Effective theoretical calculation methods in the current studies on the prediction of pressure relief protection effect of interbed coal and rock masses and their distribution laws are lacking. Thus, the evaluation and research with respect to pressure relief effect in protective seam mining relatively lag behind. This situation restricts the engineering feasibility evaluation and decision making in the protective seam mining. Therefore, the influence of upper protective seam mining on the pressure relief protection effect of coal and rock mass between underlying beds was investigated in this study. On the basis of an analysis of concrete engineering projects, a mechanical model was constructed for the pressure relief protection effect of upper protective seam mining on the coal and rock mass between underlying beds. The distribution equation of pressure relief expansion ratio in the underlying protected seam was also derived. The influence laws of main influencing factors on the pressure relief protection effect of the protected seam were revealed as well. In the end, the pressure relief effect was analyzed and verified for the protected seam before and after mining through numerical simulation and similarity simulation test. The pressure relief effect of upper protective seam mining on the coal and rock mass between underlying beds and the distribution characteristics were deeply explored in this study, which could provide a theoretical reference for the decision making in the gas extraction engineering design and pre-evaluation of extraction effect. Results show that the effective pressure relief zone (expansion rate $>0.3 \%$ ) of the protected seam beneath the goaf is located within the range of approximately $40 \mathrm{~m}$ from the coal wall to the rear part. It also presents an approximate " $\Lambda$-shaped distribution characteristic," that is, it experiences migration and evolution with the advancement in the working face. Moreover, the peak pressure relief lags behind the coal wall on the working face by nearly $10-20 \mathrm{~m}$. In the numerical simulation, the expansion ratio in the goaf also presents an approximate " $\Lambda$-shaped distribution." Its effective pressure relief zone is the $50 \mathrm{~m}$ range from the coal wall to the rear part of the goaf, and the peak value lags behind the coal wall by around $15 \mathrm{~m}$. The theoretical results and numerical simulation results are basically consistent with the physical experiment results. The expansion rates are $1.25 \%, 1.268 \%$, and $1.32 \%$, respectively. The elastic modulus $E$ of coal seam and interbed spacing $H$ are the main influencing factors of the swelling deformation and are negatively correlated with the expansion ratio. In the actual mining process, $E$ and $\mathrm{H}$ of the protected layer can be measured to infer the expansion deformation of the protected layer.
\end{abstract}

\section{Introduction}

The deep high ground stress and coal and gas outburst disaster become increasingly severe as the coal resource development and utilization extend to deep parts. During the deep mining process, the mining disturbance behaviors have a great bearing on the changes in the mechanical state of deep coal body and seepage field. Protective seam mining is an effective regional gas pressure relief method, and a large quantity of pressure relief gas at the protected seam is 
emitted into the working face and goaf via the floor cracks in the mining process; thus, extracting the pressure relief gas in the protected seam is necessary [1-5].

Domestic (Chinese) and foreign scholars have always been dedicated to the studies on protective seam pressure relief mining and coal and gas disaster. Wang et al. [6] studied the evolution laws of floor cracks in the short-distance protective seam mining. They demonstrated that the coal mass in the pressure relief and permeability improving zone had large swelling deformation and high permeability, and this zone was also an efficient pressure relief gas intercept and extraction zone. Ren et al. [7] acquired the loadcarrying condition of the protected seam through the similar material simulation test and determined the stress state after the coal seam deformation through the force analysis of the protected coal seam. They concluded that greater mining disturbance borne by the protected seam meant greater peak breaking stress of the coal mass and higher volumetric strain during the upper protective seam mining process under the same test conditions. Xue et al. [8] obtained the expression of internal displacement of the rock mass using a semi-infinite body model. They also constructed a "two-zone" crack distribution model and its simplified mechanical model to probe the pressure relief mechanism of protected seam. On the basis of a study of gas emission laws on the short-distance protective seam mining face, Wang et al. [9] optimized the pressure relief gas extraction parameters of protective seam. They obtained that the gas emissions on the protective seam mining face mostly came from the pressure relief gases at the protected seam. Zhang et al. [10] discussed the local stress concentration and rock breaking behavioral mechanisms in rock intercalation after the protective seam mining from longitudinal and transverse perspectives via numerical simulation and mechanical analysis. Under the engineering background of 10\# mine in Pingdingshan, Zhang et al. [11] studied the crack evolution laws and distribution characteristics in the coal and rock mass between two coal seams. They found that the cracks were expanded with the increase in intensity of mining activity, and most cracks developed at low angle or became parallel to the stratum. Through physical model and numerical simulation, Wang et al. [12] investigated the stress distribution and crack evolution laws in surrounding rocks during the protective seam mining process under certain mining conditions. They stated that the displacement of surrounding rock and the evolution of cracks were affected by the support pattern.

At present, extensive research has been conducted at home and abroad on the development of overburden fissure zones and gas pressure relief caused by traditional protective coal seam mining, and important research results have been obtained [13-15]. Good research progress has also been made in the expansion trend area below the mined-out area. However, with the continuous advancement of the protective layer working face, there is currently no fixed theoretical formula for the expansion rate and expansion range of coal and rock masses with different buried depths under the goaf. It is impossible to grasp the expansion and deformation at different positions of the coal and rock mass underneath the goaf during the advancement of the working face, nor can it accurately grasp the swelling area of the coal and rock mass underneath. The previous engineering experience or similar working face treatment methods are often used to determine the expansion changes of the underlying coal body, often with large deviations. Although there are related mechanical models to analyze the interaction between the protective layer and the protected layer, it still fails to reveal the specific factors that affect the expansion and deformation of the protected layer. Therefore, it is difficult to understand the real-time change law of the expanded range of the mined-out area. This paper takes the 11129 working face of Zhangji Coal Mine of Huainan Mining Group as the engineering background and explores the changing law and range of the expansion ratio of the protective layer under the goaf. The stress evolution process and the effective expansion zone change of the protected coal seam are theoretically deduced. The analytical solution of the expansion rate of the protected layer and its effective pressure relief range in the mining mode of the protective layer is given. It is verified by a combination of numerical simulation and similar simulation experiment. The research is expected to guide the engineering design and pre-evaluation decision making of protective layer mining and gas drainage pressure relief effects.

\section{Analysis of Project Profile}

The 8\# coal in east (1) mining area of Zhangji Coal Mine has complicated geological conditions and high risk of coal and gas outburst. Thus, it does not meet the direct mining conditions. Upper protective seam mining is adopted to realize pressure relief and gas extraction of $8 \#$ coal. Meanwhile, 9\# coal is mined at protective seam, where the average thickness of $9-1 \#$ coal is $1.9 \mathrm{~m}$ and that of $9-2 \#$ coal is $0.9 \mathrm{~m}$. The average thickness of dirt band is $1.4 \mathrm{~m}$, and the upper roof consists of siltstone with an average thickness of $8.0 \mathrm{~m}$. The immediate roof is composed of quartz sandstone with an average thickness of $7.6 \mathrm{~m}$. The lithology of immediate floor is mudstone with an average thickness of $2.5 \mathrm{~m}$. The lithology of lower floor is siltstone with an average thickness of $5.2 \mathrm{~m}$. The average thickness of $8 \#$ coal at the underlying protected seam is $4 \mathrm{~m}$, and it is $9 \mathrm{~m}$ away from $9 \#$ coal. The recoverable strike and inclined lengths of 11129 working face, which is the first mining face of 9\# coal, are 1,200 and $240 \mathrm{~m}$, respectively. Its burial depth from the ground is $710 \mathrm{~m}$. The general occurrence state of coal seam is a monoclinal structure, which is locally developed with secondary folds. The coal seam is generally high in the west and low in the east, and the dip angle ranges from $2^{\circ}$ to $6^{\circ}$. The comprehensive histogram of the working face is shown in Figure 1.

8 \# coal at the protected seam is of low permeability, low gas drainage rate, and complicated geological conditions. Thus, the upper protective seam mining should be conducted for $8 \#$ coal to realize gas extraction and pressure relief. (1) The coal pillars reserved in the 9\# coal goaf form displacement and stress fields in the mining process of $8 \#$ coal, which brings difficulty for the supporting and roadway layout of $8 \#$ coal working face and impedes the safety mining 


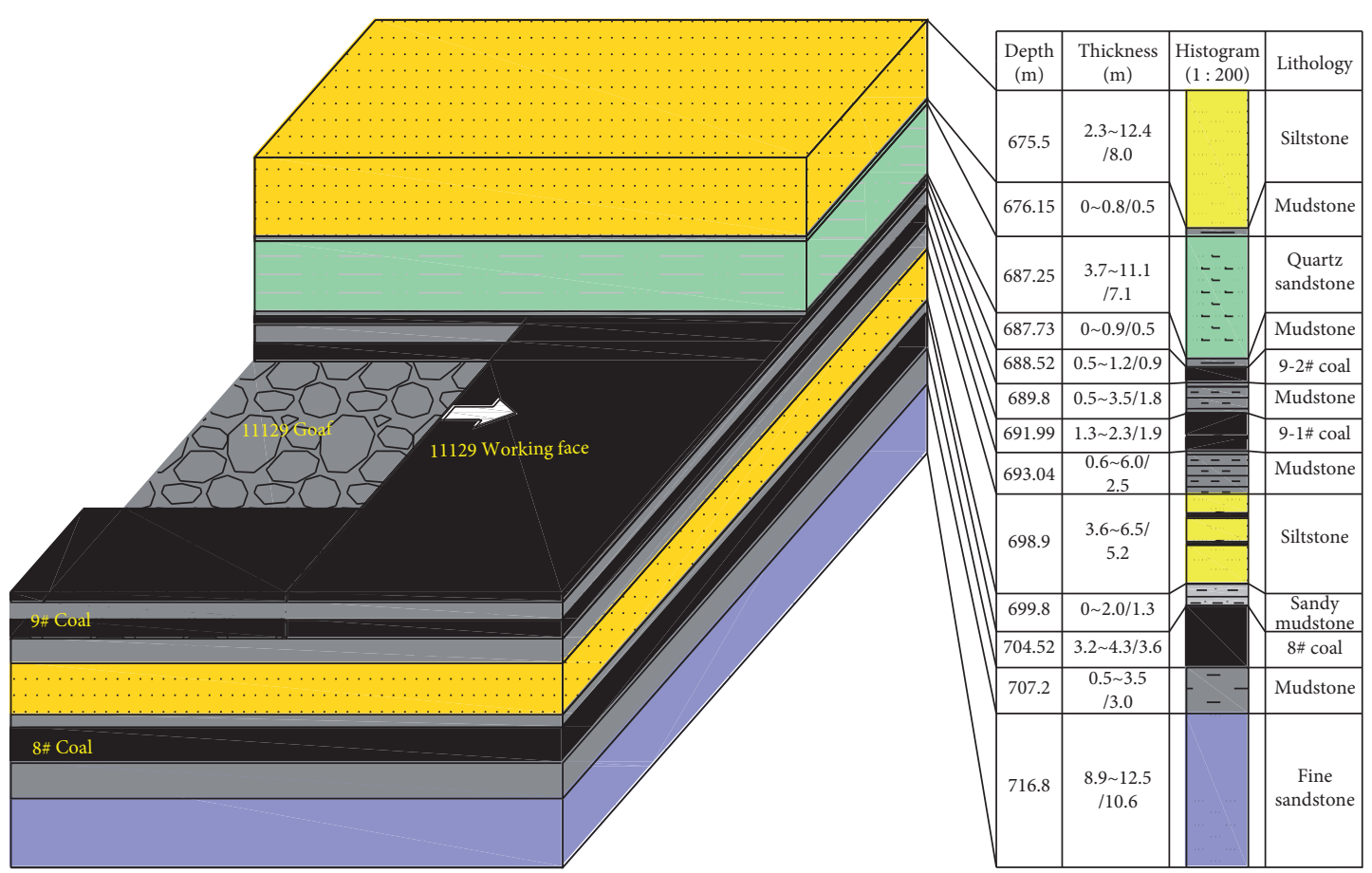

FIGURE 1: Comprehensive histogram of mining face in Zhangji Coal Mine.

and gas extraction of $8 \#$ coal. (2) During the $8 \#$ coal mining process at protected seam, the existence of $9 \#$ coal goaf will accelerate the fracture of bearing bed. As a result, the $9 \#$ coal goaf runs through 8 \# coal working face. Consequently, gas, water, and gangues in the goaf at upper coal seam are poured into 8 \# coal working face, and this condition harms the safety production of this coal mine [16]. (3) The pressure relief of $8 \#$ coal is good for gas extraction. Thus, the pressure relief zone and gas extraction engineering are closely combined to realize safe and efficient mining of $8 \#$ coal and maximize the economic benefit.

\section{Mechanical Model Analysis of Pressure Relief Protection Effect of Upper Protective Seam Mining on Coal and Rock Masses between Underlying Beds}

\subsection{Mechanical Model of Mining-Induced Stress Distribution} on the Floor of Working Face. Coal seam is usually under elastic deformation state before mining; in the mining process, the initial stress field of rock on the floor is affected by the mining, the floor in front of the working face is under the action of concentrated stress, the floor stress field is changed and redistributed, and the floor stress distribution depends on the transfer of concentrated stress in front of the working face to the lower rock mass of the coal seam floor $[17,18]$. The following assumptions are considered: the coal and rock mass under the initial stress state of rock do not influence the stress redistribution of underlying coal and rock mass, the abutment pressure in front of the working face can be regarded as the triangular banding load from the coal wall to stress peak point and the trapezoid banding load in front of the stress peak point, the floor is regarded as a uniform elastomer, and the problem is solved by a plain strain problem. The underlying rock and coal stress is then theoretically calculated [18].

To facilitate the computational analysis, the stress change in the coal mass and goaf is expressed in the form of increment:

$$
\Delta \sigma_{x}=\sigma_{x}-\sigma_{0}
$$

The initial stress of rock is deducted from formula (1), and the distribution law of the stress increment at the coal side can be obtained. The maximum value of its stress increment is $(k-1) P$, while that in the goaf is $-P$. Thus, the distribution law of abutment pressure increment in coal body on the working face and the goaf can be acquired [19], as shown in Figures 2 and 3.

The expression of vertical stress is [19]

$$
P(\xi)=m \xi+n \text {. }
$$

According to the equilibrium of elastic mechanics, the equilibrium can be reached only when the following condition is satisfied:

$$
\left(d_{1}+d_{2}\right) \frac{k-1}{2} P=d_{3} P+\frac{d_{4}}{2} P .
$$

The following condition is then solved:

$$
d_{1}+d_{2}=\frac{2 d_{3}+d_{4}}{k-1}
$$

To solve the stress at one point $M$ within the half planar body, the coordinate axes are taken as shown in Figure 3, and the coordinates of point $M$ are $(x, y)$. A minimum 


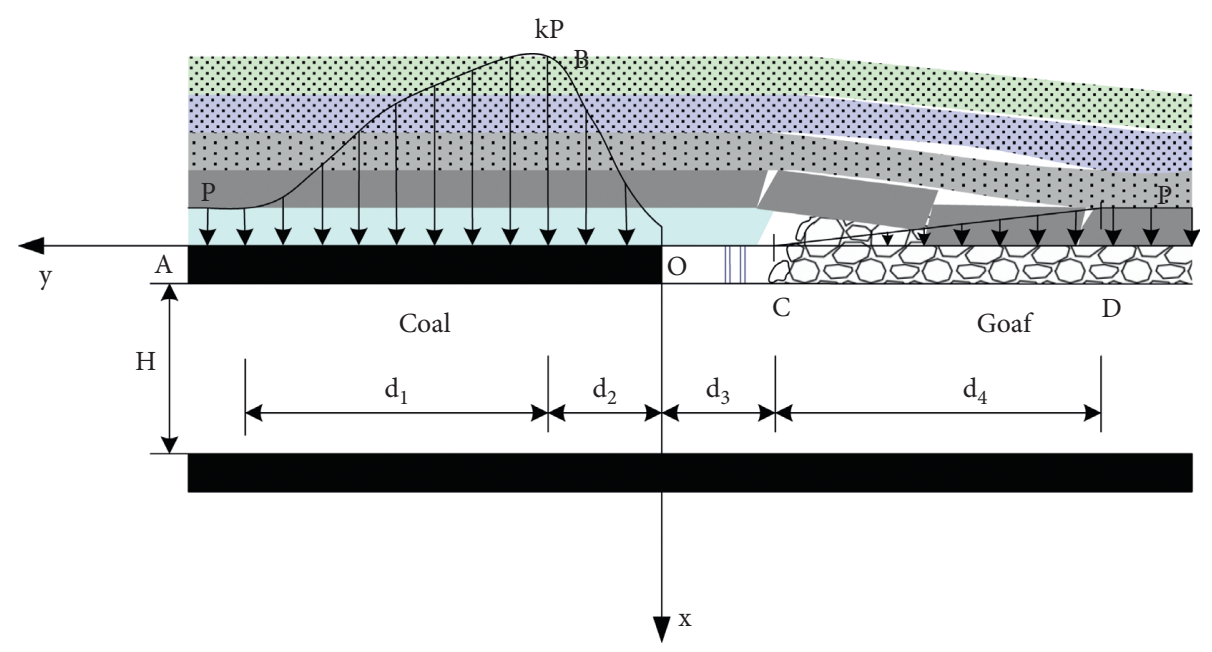

FIgURE 2: Abutment pressure distribution graph before and behind the working face.

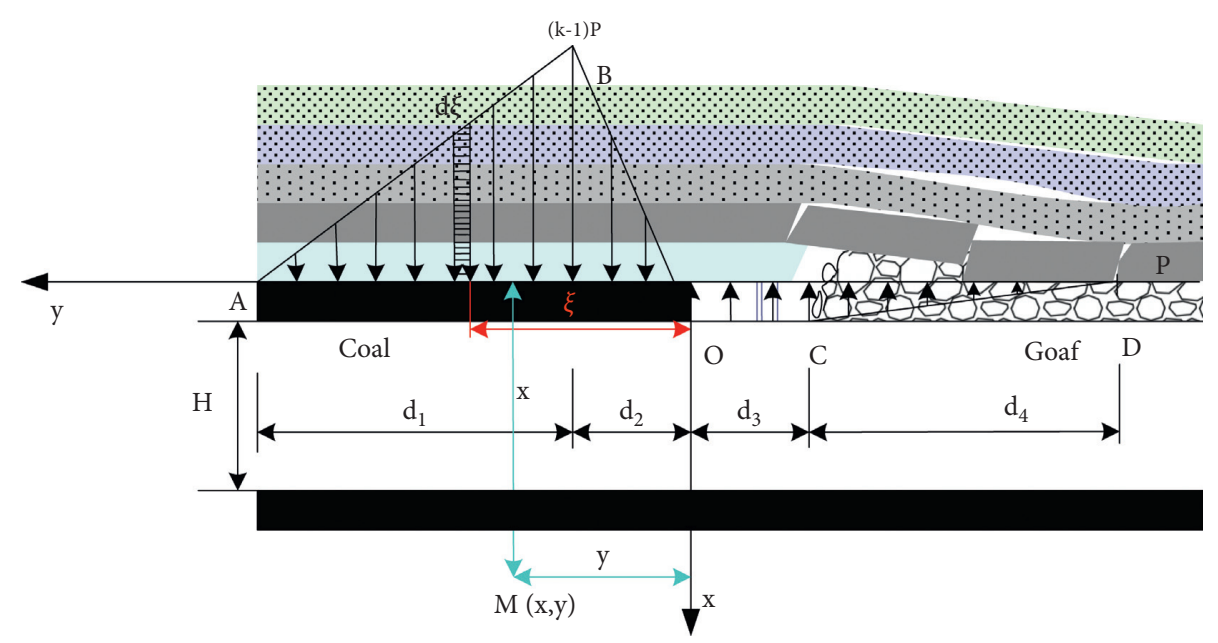

FIgURE 3: Simplified additional stress distribution graph before and behind the working face. $P$-vertical initial stress of rock, $\gamma H$; $d_{1}-$ length from peak advanced abutment pressure to the abutment pressure falling within the initial stress zone of rock; $d_{2}-$ length from coal wall of the working face to the peak abutment pressure; $d_{3}$-length of goaf with zero initial stress of rock; $d_{4}$-length from residual abutment pressure in the goaf until the initial stress of rock is recovered; and $H$-interbed spacing.

length $\mathrm{d} \xi$ is taken at the place with a distance of $\xi$ from the origin of coordinates $O$ on the straight line $O y$. The force $\mathrm{d} P=q \mathrm{~d} \xi$ it bears is regarded as a minimal concentrated force, and the vertical and horizontal distances from point $M$ to this minimal concentrated force $\mathrm{d} P$ are $x$ and $y-\xi$, respectively. Thus, the stress caused by the minimal concentrated force $\mathrm{d} F=q \mathrm{~d} \xi$ at point $M$ is as observed in the following formula:

$$
\left.\begin{array}{c}
\mathrm{d} \sigma_{x}=-\frac{2 q d \xi}{\pi} \frac{x^{3}}{\left[x^{2}+(y-\xi)^{2}\right]^{2}} \\
\mathrm{~d} \sigma_{y}=-\frac{2 q d \xi}{\pi} \frac{x(y-\xi)^{2}}{\left[x^{2}+(y-\xi)^{2}\right]^{2}}
\end{array}\right\} .
$$

The stresses caused by all minimal concentrated forces are superposed to solve the vertical and horizontal stress distributions in front of the working face. Therefore, the integral equation of formula (5) is obtained as follows:

$$
\left.\begin{array}{c}
\sigma_{x}=-\frac{2}{\pi} \int \frac{p(\xi) x^{3} d \xi}{\left[x^{2}+(y-\xi)^{2}\right]^{2}} \\
\sigma_{y}=-\frac{2}{\pi} \int \frac{p(\xi) x(y-\xi)^{2} d \xi}{\left[x^{2}+(y-\xi)^{2}\right]^{2}}
\end{array}\right\} .
$$

The vertical and horizontal stresses are solved using formula (6).

The equation for the mining-induced stress distribution in the surrounding rocks on the floor perpendicular to the working face is

$$
\sigma_{x}=-\frac{2}{\pi} \int \frac{(m \xi+n) x^{3} d \xi}{\left[x^{2}+(y-\xi)^{2}\right]^{2}}
$$


The following condition is then solved:

The equation for the mining-induced stress distribution in the surrounding rocks on the floor in the advancement direction of the working face is

$$
\sigma_{x}=\left\{-\frac{m x^{3}+(y-\xi)(m y+n) x}{\pi\left[x^{2}+(y-\xi)^{2}\right]^{2}}-\frac{(m y+n)}{\pi} \arctan \left(\frac{y-\xi}{x}\right)\right\} \mid\left(\begin{array}{c}
d_{1}, \\
d_{2}, \\
d_{3}, \\
d_{4}
\end{array}\right)
$$

$$
\sigma_{y}=-\frac{2}{\pi} \int \frac{(m \xi+n) x(y-\xi)^{2} \mathrm{~d} \xi}{\left[x^{2}+(y-\xi)^{2}\right]^{2}}
$$

The following condition can be solved:

$$
\sigma_{y}=-\frac{x}{\pi}\left\{\frac{m\left[x^{2}+y(y-\xi)\right]+n(y-\xi)}{x^{2}+(y-\xi)^{2}}+\frac{n+m y}{x} \arctan \left(\frac{y-\xi}{x}\right)-m \log \left[x^{2}+(y-\xi)^{2}\right]\right\} \mid d_{1}, d_{2}, d_{3}, d_{4} \text {. }
$$

3.2. Mechanical Relation of Upper Protective Seam Mining with the Pressure Relief Protection Effect of Coal and Rock Masses between Underlying Beds. According to the physical and geometric equations in the plane strain problem of the elastic mechanics, the vertical displacement can be solved as follows:

$$
\begin{aligned}
u_{x}= & \int \varepsilon_{x} \mathrm{~d} x=\int \frac{1-\mu^{2}}{E}\left(\sigma_{x}-\frac{\mu}{1-\mu} \sigma_{y}\right) \mathrm{d} x \\
= & \frac{1}{2 \pi E}\left\{2 x(m y+n)\left(2 \mu^{2}+\mu-1\right) \arctan \left(\frac{y-\xi}{x}\right)\right. \\
& \left.\left.+(1+\mu)\left[m x^{2}(3 \mu-1)+\left(-\mu m x^{2}+(y-\xi)(m y(\mu-1)+n(4 \mu-2)+m \xi(3 \mu-1)) \log \left[x^{2}+(y-\xi)^{2}\right]\right)\right]\right\}\right]\left(\begin{array}{c}
d_{1}, \\
d_{2}, \\
d_{3}, \\
d_{4}
\end{array}\right)
\end{aligned}
$$

where $m$ and $n$ are stress coefficients of $P(\xi)$ corresponding to $d_{1}, d_{2}, d_{3}$, and $d_{4} ; E$ is the elastic modulus; $\mu$ is Poisson's ratio; and $K$ is a constant.

The floor stress distribution in the advancement direction of the working face is divided into four stress zones: $A B, B O$, $\mathrm{OC}$, and $\mathrm{CD}$. The integrals of the abovementioned formulas are solved. Then, complete stress distribution, strain, and displacement equations in vertical direction of the floor can be obtained.

In the protective seam mining process, the displacements of 8 \# coal roof and floor are calculated using the aforementioned formula, and the expansion ratio $Q$ is further calculated as 


$$
\begin{aligned}
Q= & \frac{\Delta u}{h} \times 100 \% \\
= & \frac{100 \%}{2 \pi h E}\left\{\left\{2 x(m y+n)\left(2 \mu^{2}+\mu-1\right) \arctan \left(\frac{y-\xi}{x}\right)\right.\right. \\
& \left.+(1+\mu)\left[m x^{2}(3 \mu-1)+\left(-\mu m x^{2}+(y-\xi)(m y(\mu-1)+n(4 \mu-2)+m \xi(3 \mu-1)) \log \left[x^{2}+(y-\xi)^{2}\right]\right)\right]\right\} \mid \\
& \left.\cdot\left(d_{1}, d_{2}, d_{3}, d_{4}\right)\right\} \mid\left(x_{=a}-x_{=a+h}\right),
\end{aligned}
$$

where $\Delta u$ is the displacement difference between roof and floor of the protected seam, $\mathrm{m}$; $h$ is the average thickness of protected seam, $\mathrm{m}$; and $a$ is the distance from protective seam to the roof of protected seam, $m$.

The fluctuation of expansion ratio $Q$ can reflect the evolution law of pressure relief at the protected seam, and $Q>0.3 \%$ is taken as an effective pressure relief zone.

\section{Influence Factor Analysis of Upper Protective Seam Mining on Pressure Relief Protection Effect of Protected Seam}

The pressure relief effect of the protected seam is mainly related to stress concentration coefficient $k$, elastic modulus $E$ of coal seam, coal seam thickness $h$, and interbed spacing $H$. According to the mine ground pressure laws and geological structural conditions, the engineering parameter $k$ is taken as $2.5, \mu$ value is $0.3, E=1 \mathrm{GPa}, h=4 \mathrm{~m}, H=9 \mathrm{~m}$, $d_{1}=30 \mathrm{~m}, d_{2}=10 \mathrm{~m}, d_{3}=10 \mathrm{~m}$, and $d_{4}=40 \mathrm{~m}$. After external and human factors are excluded, different parameters are taken to comparatively analyze the changes in the roof stress and expansion ratio of $8 \#$ coal, as shown in Table 1 and Figures 4-11.

As shown above, the concentrated stress coefficient $k$ mainly influences the abutment pressure in front of the coal wall, and it is in direct proportion to the abutment pressure. With the continuous increase in the coefficient $k, 8 \#$ coal beneath the abutment pressure goes through swelling deformation, which has a very minor influence on the stress and swelling deformation in the rear goaf. Under $k=2.5$, the maximum increment of abutment pressure in front of the coal wall is $18.5 \mathrm{MPa}$. As the elastic modulus is continuously increased, no influence is generated on the stress change of the protected seam, and the expansion ratio is gradually reduced. Moreover, the elastic modulus becomes inversely proportional to expansion ratio, and it is the result of joint action of coal seam properties and surrounding environment. Before the protective seam mining, the elastic modulus of the protected seam should be measured in advance to estimate the overall swelling deformation of the protected seam during the protective seam mining process. During the upper protective seam mining process, the change in the thickness of overlying coal seam has no obvious influence on the overall stress change or swelling deformation. As a result, the thickness of coal seam is not the primary influencing factor of the swelling deformation. With the increase in the burial depth of the protected seam, the downward stress propagation is continuously reduced with the increase in interbed spacing, the swelling deformation is gradually mitigated, and the peak swelling deformation is gradually distant from the coal wall. The scopes of influence at two sides are also slightly enlarged, and both approach 0 in the end.

In summary, the main influencing factors of the swelling deformation of the protected seam are elastic modulus $E$ of the coal seam and interbed spacing $\mathrm{H}$. Other factors exert minor influences. In the actual mining process, the layer spacing $\mathrm{H}$ can be estimated, and the underlying coal rock mass is sampled by drilling holes into the protected layer. The mechanical properties of the rock samples were tested using the MTS rock mechanical performance testing machine, and the stress-strain curves of the rock samples were obtained, and then the elastic modulus $E$ of the underlying coal rock mass was obtained.

\section{Instance Analysis of Upper Protective Seam Mining Project in Zhangji Coal Mine}

5.1. Example Calculation of Protective Seam Mining on 11129 Working Face of Zhangji Coal Mine. According to the geological conditions of 11129 working face and mine ground pressure law, the distance from the coal wall of the working face to the peak stress concentration is $d_{2}=10 \mathrm{~m}$, the distance from the peak stress concentration to the initial stress zone of rock in deep coal and rock mass in the front is $d_{1}=30 \mathrm{~m}$, the spatial width of the working face is $d_{3}=10 \mathrm{~m}$, the distance from the goaf to the initial stress zone of rock in the rear deep compacted goaf is solved as $d_{4}=40 \mathrm{~m}$, the stress concentration coefficient $k$ is taken as 2.5 , the initial stress of rock is $19 \mathrm{MPa}$, and the distance from the working face to the origin is $40 \mathrm{~m}$. The aforementioned formula was used to calculate the displacement change of the roof and floor of the protected seam beneath the floor in the advancement direction of the working face. Mathematical software Wolfram Mathematica was used to solve the OA, $\mathrm{AB}, \mathrm{BC}$, and $\mathrm{CD}$ segments. The total vertical stress was obtained through the superposition, and the integral was taken to solve the vertical displacement. 
TABLE 1: Values of different influencing factors.

\begin{tabular}{lccc}
\hline Stress concentration coefficient, $k$ & Elastic modulus, $E(\mathrm{GPa})$ & Coal thickness, $h(\mathrm{~m})$ & Interbed spacing, $H(\mathrm{~m})$ \\
\hline 1.5 & 0.5 & 2 & 5 \\
2 & 1 & 3 & 13 \\
2.5 & 1.5 & 4 & 21 \\
3 & 2 & 5 & 25 \\
\hline
\end{tabular}

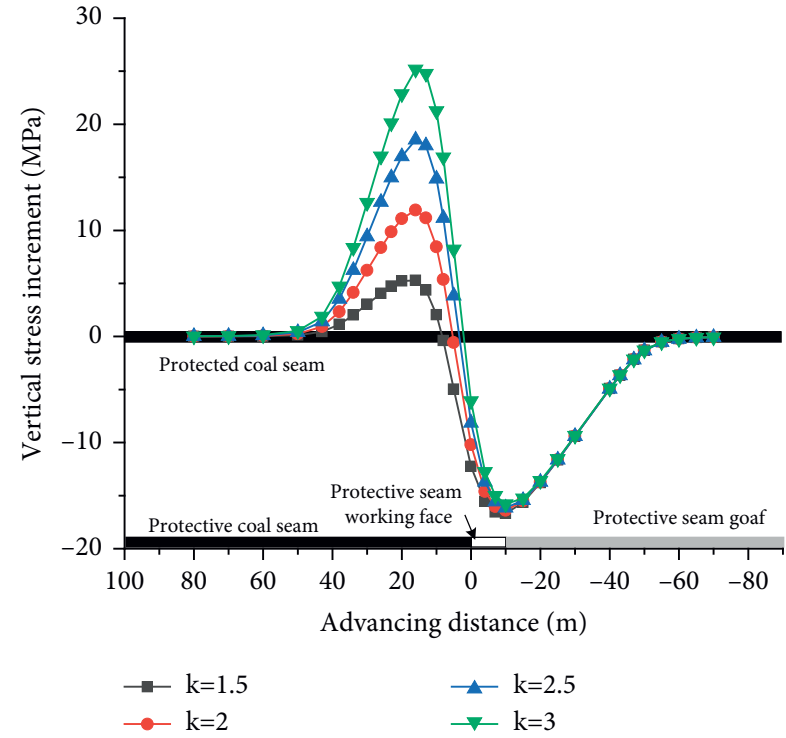

FIGURE 4: Different stress concentration coefficient stress variation curves.

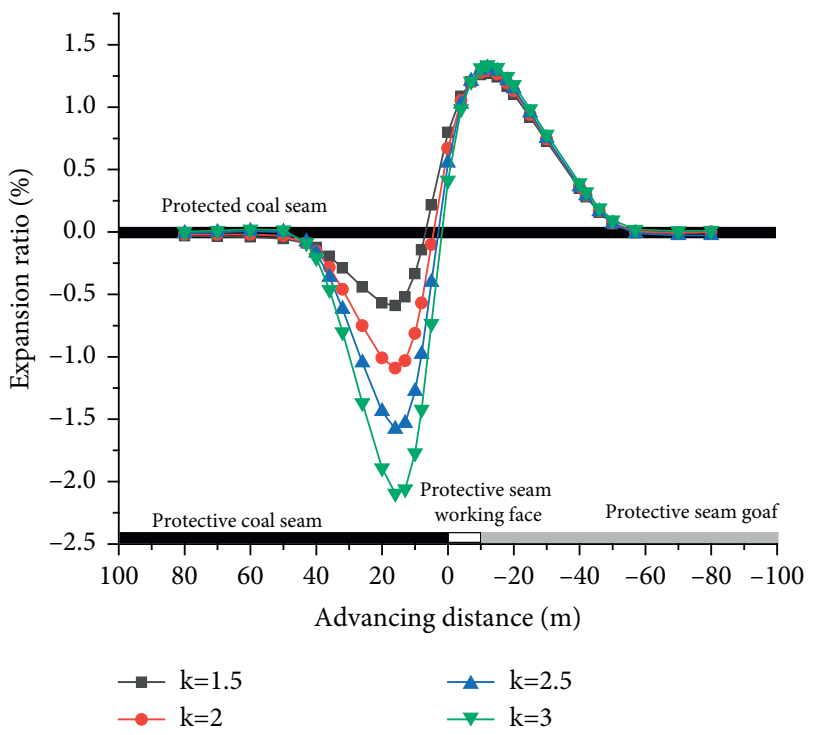

Figure 5: Variation curve of expansion rate with different stress concentration coefficients.

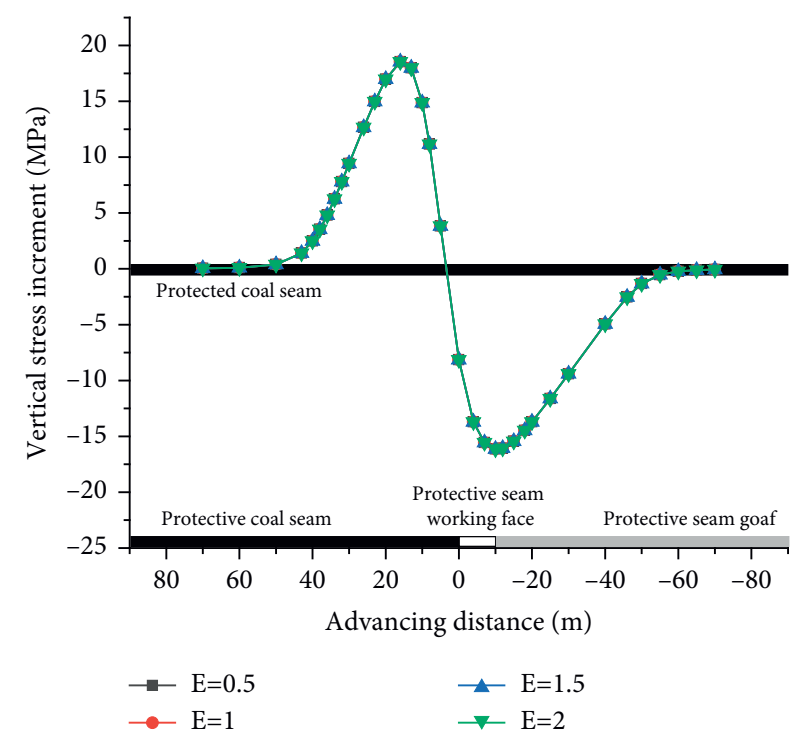

Figure 6: Different elastic modulus stress change curves.

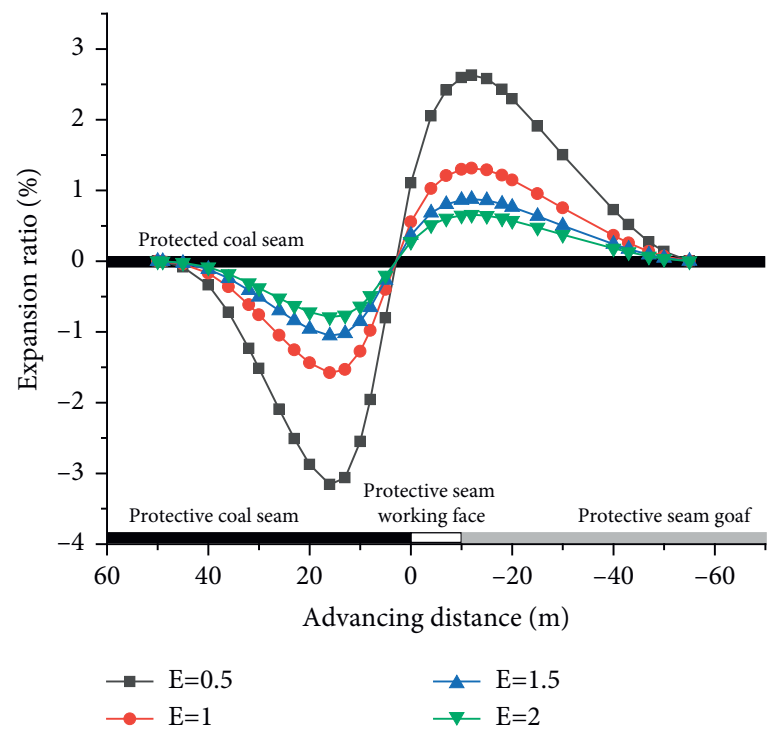

FIgURE 7: Variation curve of expansion rate with different elastic moduli. 


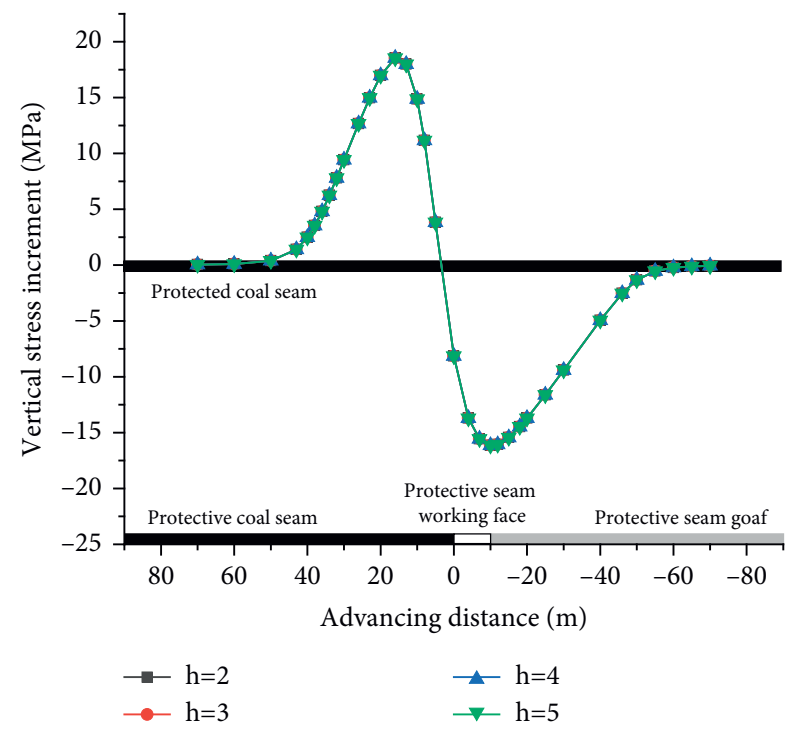

FIGURE 8: Stress variation curves of different coal thicknesses in the protected layer.

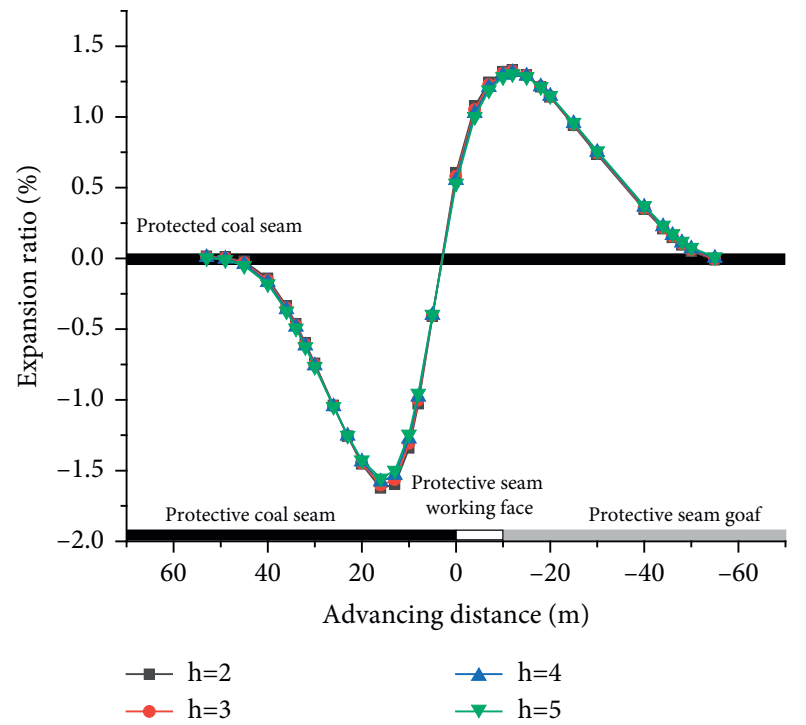

FIGURE 9: Variation curve of expansion rate of different coal thicknesses in the protected layer.

The expression of vertical displacement in different phases is

$$
\left\{\begin{array}{l}
O A: p(\xi)=-0.95 \xi, \\
A B: p(\xi)=-4.75 \xi+171, \\
B C: p(\xi)=-19, \\
C D: p(\xi)=-0.475 \xi-42.75
\end{array}\right.
$$

The vertical stress $\Delta \sigma_{x}$ of the protected seam is

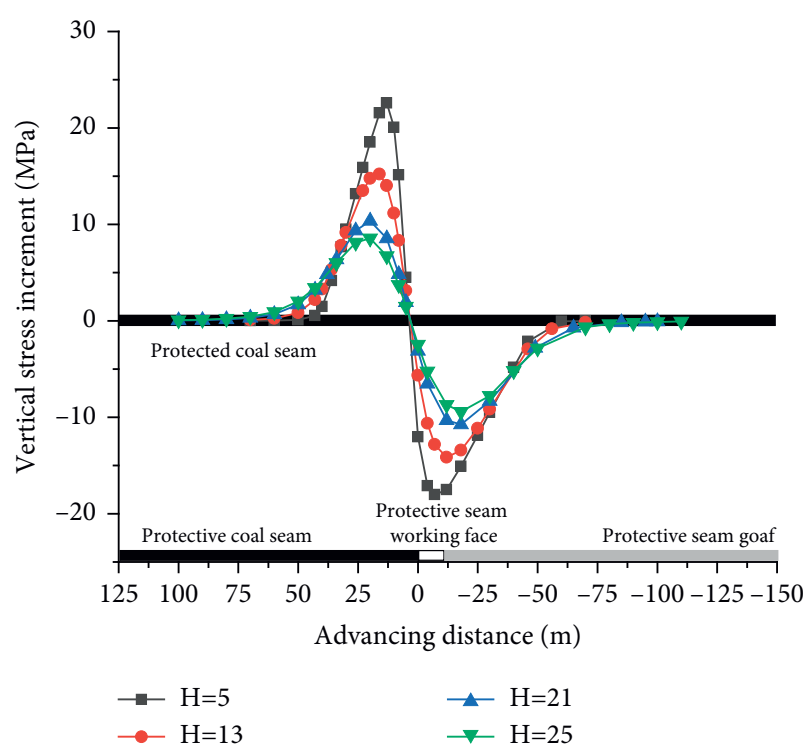

Figure 10: Stress variation curve diagram of different buried depths.

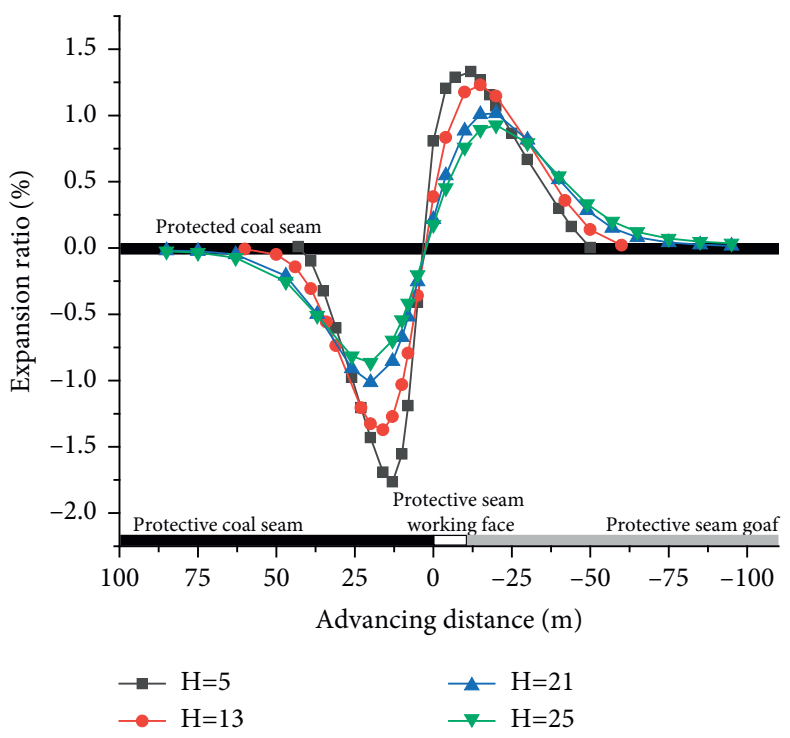

FIGURE 11: Variation curve of expansion rate at different buried depths.

$$
\begin{aligned}
\Delta \sigma_{x}= & \sigma_{x 1}+\sigma_{x 2}+\sigma_{x 3}+\sigma_{x 4}=\frac{19(C-D)}{\pi}+0.1512 x \\
& +B(-54.431-1.512 y) \\
& +F(-13.608-0.151 y)+D(13.608+0.151 y) \\
& +0.302 y(A-B)+C(54.431+1.512 y)
\end{aligned}
$$




$$
\begin{aligned}
& +\frac{x\left[-1632.93-1.814 x^{2}+y(-108.862-1.814 y)\right]}{x^{2}+(30+y)^{2}} \\
& +\frac{19 x}{\pi}\left[\frac{40+y}{x^{2}+(40+y)^{2}}-\frac{50+y}{x^{2}+(50+y)^{2}}\right] \\
& +\frac{x\left[608.387+0.151 x^{2}+y(21.168+0.151 y)\right]}{x^{2}+(50+y)^{2}} \\
& +\frac{x\left[2177.24+1.512 x^{2}+y(114.91+1.512 y)\right]}{x^{2}+(40+y)^{2}},
\end{aligned}
$$

where

$$
\begin{aligned}
& A=\arctan \frac{y}{x}, B=\arctan \frac{30+y}{x}, C=\arctan \frac{40+y}{x}, \\
& D=\arctan \frac{50+y}{x}, F=\arctan \frac{90+y}{x} .
\end{aligned}
$$
is

$$
\begin{aligned}
u_{x}= & \int \varepsilon_{x} d x \\
= & -0.74298 B+1.10072 C+0.221126 D-0.557237 H \\
& +B\left[-0.000354 x^{2}+y(-0.049532-0.000826 y)\right]+H\left[-29 \times 10^{-6} x^{2}+y(-0.01238-0.0000688 y)\right] \\
& +D\left[-29 \times 10^{-6} x^{2}+y(0.007826+0.0000688 y)\right] \\
& +C\left[0.0002948 x^{2}+y(0.055036+0.000688 y)\right] \\
& +A\left(0.000059 x^{2}+0.0001376 y^{2}\right) \\
& +x\left[0.000157 y \operatorname{arctasn} \frac{y}{x}+(-0.0283-0.00094 y) \arctan \frac{30+y}{x}\right. \\
& \left.+(0.031449+0.000786 y) \arctan \frac{40+y}{x}+(0.003931+0.000079 y) \arctan \frac{50+y}{x}+(-0.007076-0.000079 y) \arctan \frac{90+y}{x}\right]+K
\end{aligned}
$$

where

$$
\begin{aligned}
& A=\log \left[x^{2}+y^{2}\right], B=\log \left[x^{2}+(30+y)^{2}\right], \\
& C=\log \left[x^{2}+(40+y)^{2}\right], \\
& D=\log \left[x^{2}+(50+y)^{2}\right], H=\log \left[x^{2}+(90+y)^{2}\right] .
\end{aligned}
$$

The change in the roof and floor displacement is calculated. Then, the formula of expansion ratio $Q$ at the protected seam is further solved as

$$
Q=\frac{\Delta u}{h} \times 100 \%=\frac{u_{x=9}-u_{x=13}}{h} \times 100 \% .
$$

According to the aforementioned calculation results, the change charts of the roof and floor displacement of the protected seam and the expansion ratio are drawn as shown in Figures 12 and 13.

The distribution environment of roof and floor displacement changes in 8 \# coal was analyzed, as shown in Figure 12. As the upper protective seam mining was influenced by the abutment pressure concentration on the front coal seal, 8\# coal undertook increasing vertical pressure. Its roof and floor displacements reached the maximum values of 0.32 and $0.26 \mathrm{~m}$, respectively. With the stress relief of surrounding rocks in the goaf behind the coal wall, underlying 8 \# coal experienced upward swelling deformation. The maximum deformation of the top plate is $0.34 \mathrm{~m}$ at $15 \mathrm{~m}$ behind the coal wall, and the maximum deformation of the bottom plate is $0.289 \mathrm{~m}$ at $18 \mathrm{~m}$ behind the coal wall. The expansion deformation value of the top and bottom plates of the protected layer gradually attenuates as it approaches and moves away from the coal wall and eventually approaches zero.

On the basis of Figure 13, the change curve chart of expansion ratio at the protective seam beneath the floor of the working face was analyzed. The protective seam mining facilitated the stress relief of surrounding rocks on the floor behind the coal wall and was influenced by the downward transfer of abutment pressure on the front coal wall. The coal and rock mass on the working face and that beneath the goaf went through swelling deformation, and the expansion ratio of underlying coal and rock mass reached the maximum value of $1.25 \%$ at the place $12 \mathrm{~m}$ behind the coal wall. With the advancement in the working face, the expansion ratio of overlying coal and rock mass was gradually reduced and approached 0 . The effective scope of expansion (expansion 


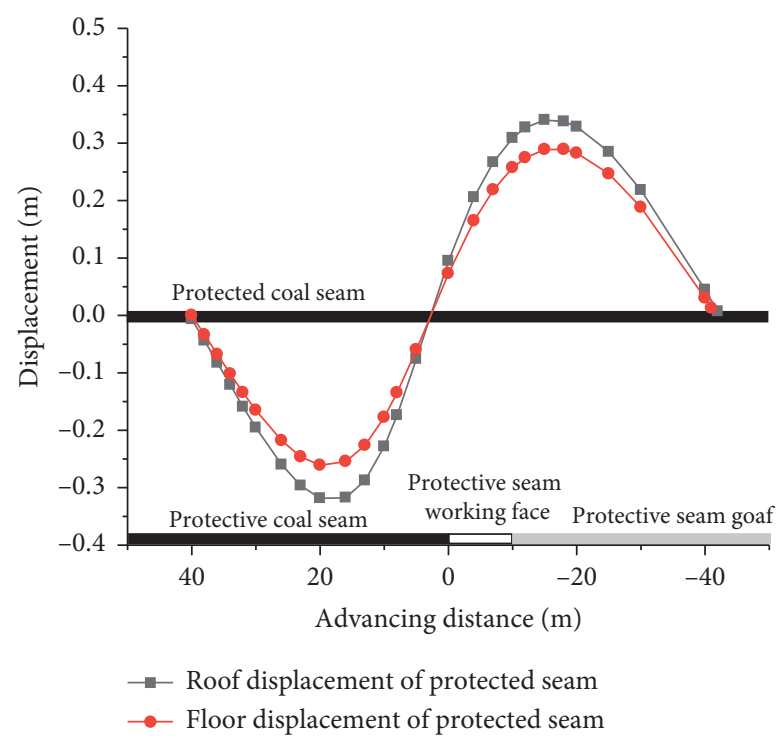

Figure 12: Curve of displacement change of the top and bottom plates of the protected layer.

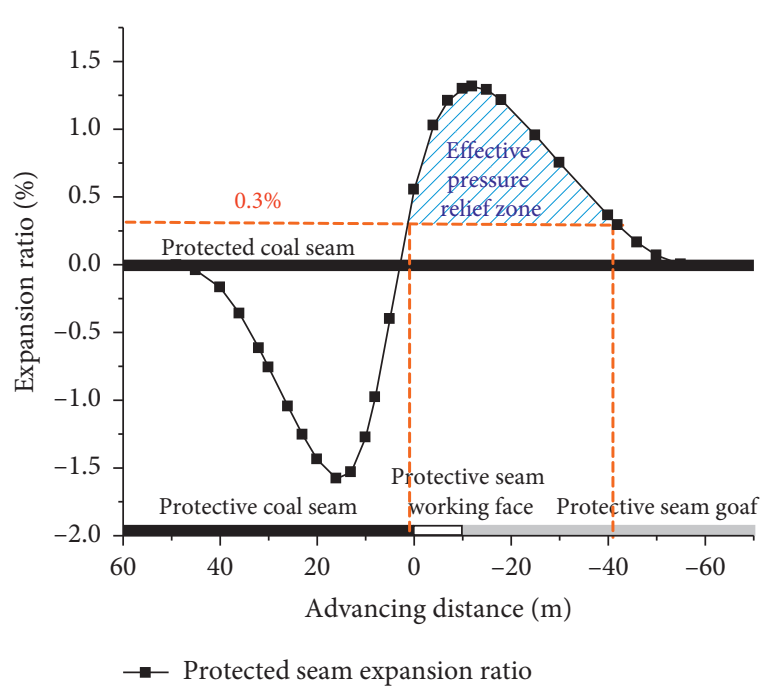

FIgURE 13: Change curve of expansion rate of protected layer.

ratio $>0.3 \%$ ) was from the coal wall to the place $40 \mathrm{~m}$ behind the coal wall, and the floor heaving was the most obvious in this scope. Meanwhile, the pressure relief effect of the protected seam was the best.

\subsection{Simulation Analysis of Protective Seam Mining Effect on} 11129 Working Face in Zhangji Coal Mine. A numerical model was established via FLAC3D numerical simulation software, with dimensions of $540 \mathrm{~m} \times 1000 \mathrm{~m} \times 169 \mathrm{~m}$ (Figure 14). The mechanical properties of rock samples were tested by MTS rock mechanical property testing machine, and the stress-strain curve of rock samples was obtained. The elastic modulus can be solved by slope. In order to ensure the reliability of data, the average value of three lithologic experiments in each group is taken. The mechanical parameters of the roof and floor are shown in Table 2. Fixed horizontal displacement constraints were set at the bottom edge, front, back, left, and right boundaries of the model. The Mohr-Coulomb failure criterion was also adopted to analyze the mechanical characteristics of coal and rock mass in this model. Domestic and foreign scholars have conducted several experiments and studies on the abutment effect of equivalent filled rock mass in goafs [20-24]. In the present study, the goaf was simulated with double-yield model. The stress-strain relation of the rock mass in the goaf is presented in Table 3, and the mechanical parameters of the rock mass in the double-yield goaf are presented in Table 4.

The advancement in 11129 working face from the openoff cut along the strike (positive direction of axis y) was simulated, the open-off cut was nearly $200 \mathrm{~m}$ from the boundary, and the influence of boundary effect was eliminated. The excavation step size was $25 \mathrm{~m}$, the goaf was filled, balanced, and advanced by $600 \mathrm{~m}$ along the strike, and the mining was stopped at $y=800 \mathrm{~m}$. The displacement changes of 8 \# coal roof and floor at $9 \mathrm{~m}$ beneath it during the mining process are shown in Figures 15-19.

Figures 15-17 shows that with the advancement in the working face, a goaf was formed, the stress was redistributed, and an abutment pressure zone higher than the initial stress of rock was formed in the coal and rock mass around the goaf. The surrounding coal and rock masses subsided, and the overlying coal and rock mass in the goaf experienced upward swelling deformation. The overall displacement was large at two sides and small in the middle, and that in the middle presented a waved change. The maximum floor heaving amounts of underlying $8 \#$ coal roof and floor in the goaf were 0.268 and $0.215 \mathrm{~m}$, respectively. The maximum 


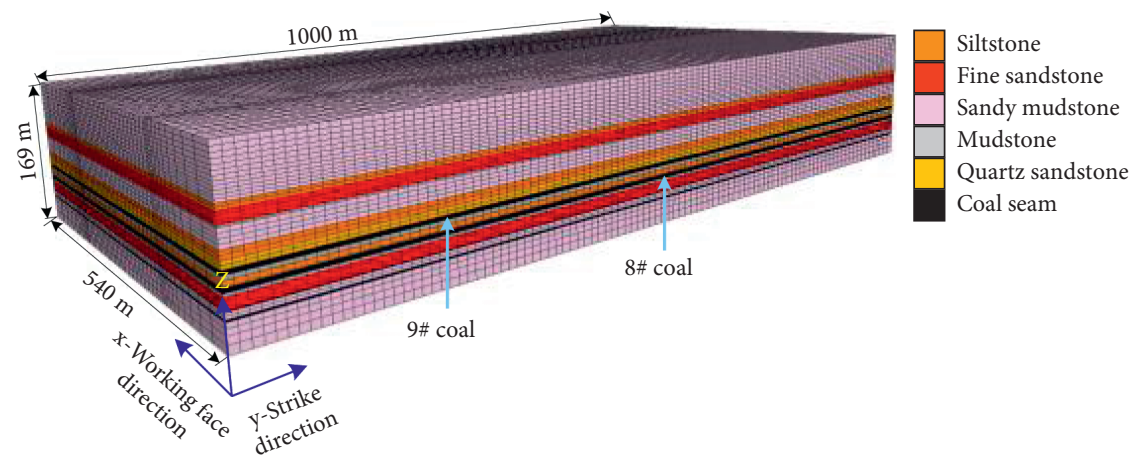

Figure 14: 3D numerical simulation model.

TABle 2: Mechanical parameters of roof and floor rock strata at the coal seam.

\begin{tabular}{|c|c|c|c|c|c|c|}
\hline Lithology & $\begin{array}{l}\text { Density } \\
\left(\mathrm{kg} / \mathrm{m}^{3}\right)\end{array}$ & $\begin{array}{l}\text { Bulk modulus } \\
(\mathrm{GPa})\end{array}$ & $\begin{array}{l}\text { Shear modulus } \\
(\mathrm{GPa})\end{array}$ & $\begin{array}{l}\text { Tensile strength } \\
(\mathrm{MPa})\end{array}$ & $\begin{array}{c}\text { Cohesion } \\
(\mathrm{MPa})\end{array}$ & $\begin{array}{c}\text { Internal friction angle } \\
\left(\left(^{\circ}\right)\right.\end{array}$ \\
\hline $\begin{array}{l}\text { Sandy } \\
\text { mudstone }\end{array}$ & 2605 & 2.16 & 1.69 & 0.38 & 2.6 & 27 \\
\hline Siltstone & 3211 & 10.48 & 8.19 & 0.44 & 2.85 & 28 \\
\hline $\begin{array}{l}\text { Quartz } \\
\text { sandstone }\end{array}$ & 2600 & 21.03 & 13.53 & 0.47 & 2.8 & 30 \\
\hline $9-2 \#$ coal & 1300 & 0.83 & 0.38 & 0.29 & 1.8 & 24 \\
\hline Mudstone & 2554 & 3.23 & 1.85 & 0.32 & 2.2 & 28 \\
\hline 9-1\# coal & 1300 & 0.83 & 0.38 & 0.29 & 1.8 & 24 \\
\hline Mudstone & 2554 & 3.23 & 1.85 & 0.32 & 2.2 & 28 \\
\hline Siltstone & 3211 & 10.48 & 8.19 & 0.44 & 2.85 & 28 \\
\hline $\begin{array}{l}\text { Sandy } \\
\text { mudstone }\end{array}$ & 2605 & 2.16 & 1.69 & 0.38 & 2.6 & 27 \\
\hline 8\# coal & 1300 & 0.83 & 0.38 & 0.29 & 1.8 & 24 \\
\hline Mudstone & 2554 & 3.23 & 1.85 & 0.32 & 2.2 & 28 \\
\hline
\end{tabular}

TABLE 3: Stress-strain relation of rock mass in the double-yield model goaf.

\begin{tabular}{lccccc}
\hline Strain & Stress $(\mathrm{MPa})$ & Strain & Stress $(\mathrm{MPa})$ & Strain & 0.13 \\
0.01 & 0.37 & 0.07 & 4.00 & 0.14 & 15.9 \\
0.02 & 0.79 & 0.08 & 5.01 & 0.15 & 21.2 \\
0.03 & 1.26 & 0.09 & 6.25 & 0.16 & 0.17 \\
0.04 & 1.80 & 0.10 & 7.79 & 0.7 \\
0.05 & 2.42 & 0.11 & 9.75 & \\
0.06 & 3.15 & 0.12 & 12.3 & \\
\hline
\end{tabular}

TABLE 4: Mechanical parameters of main rock materials in the goaf.

\begin{tabular}{lccccc}
\hline Category & Density $\left(\mathrm{kg} / \mathrm{m}^{3}\right)$ & Bulk modulus $(\mathrm{GPa})$ & Shear modulus $(\mathrm{GPa})$ & Internal friction angle $\left({ }^{\circ}\right)$ & Dilatancy angle $\left({ }^{\circ}\right)$ \\
\hline Value & 2000 & 11.1 & 8.3 & 13 & 7 \\
\hline
\end{tabular}

abutment pressure borne by the coal wall around 8\# coal beneath the goaf was $37.4 \mathrm{MPa}$, which was higher than the initial stress $(18.4 \mathrm{MPa})$ of rock. The marginal position of the goaf carried the minimum stress, and the stress in the middle of the goaf was gradually increased [25-27].

As shown in Figures 18 and 19, the overall central displacements of the roof and floor fluctuated within $0.1-0.2 \mathrm{~m}$ and $0.07-0.15 \mathrm{~m}$, the overall average expansion ratio was $1.286 \%$ when the mining face was advanced by $600 \mathrm{~m}$, and the scope of influence of average expansion was from the coal wall to $50 \mathrm{~m}$ behind the coal wall. The peak pressure relief lagged behind the coal wall by nearly $20 \mathrm{~m}$, and it presented an " $\Lambda$-shaped distribution" on the whole. With the advancement in the working face, the goaf was gradually compacted, and local rebounding and recompaction process existed within a small scope.

5.3. Similarity Simulation Test Analysis of Protective Seam Mining Effect of 11129 Working Face in Zhangji Coal Mine. 


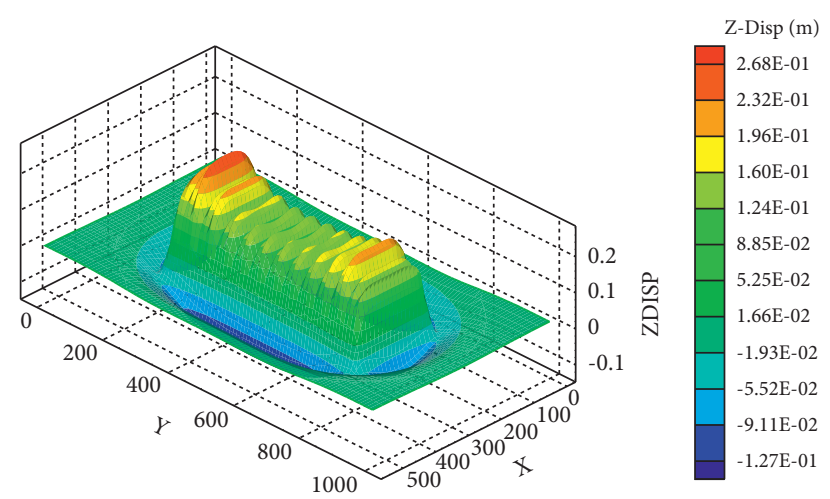

FIgURE 15: Simulation diagram of the displacement of the protected roof.

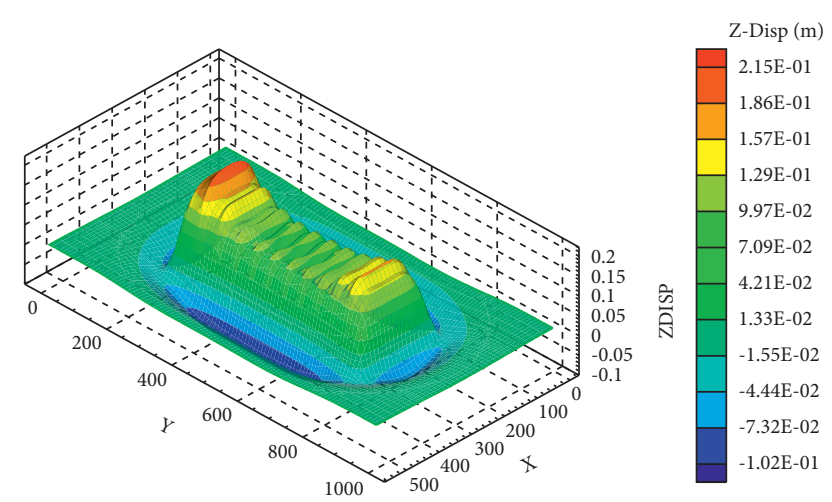

FIGURE 16: The simulation diagram of the displacement change of the protected bottom plate.

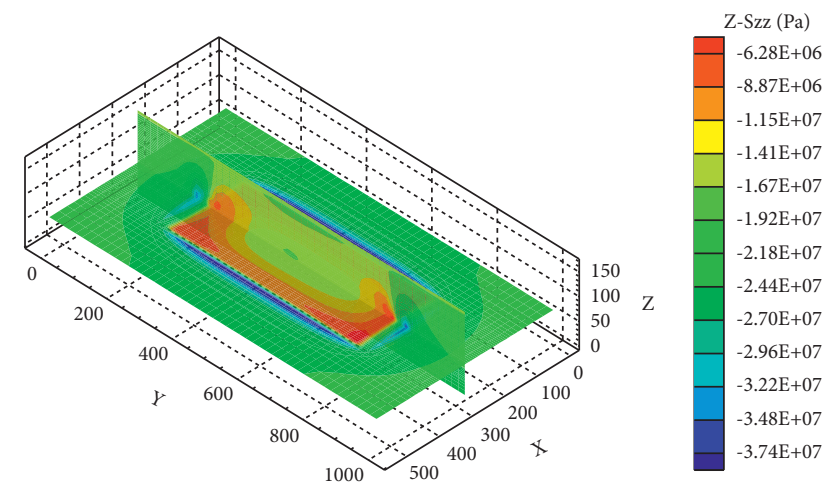

FIGURE 17: The stress change simulation diagram of the protected roof.

The similarity simulation test was conducted under the engineering background of 9\# coal at the upper protective seam and $8 \#$ coal at the protected seam in Zhangji Coal Mine. The model testbed was made of steel frame with dimensions of $3.0 \mathrm{~m}$ (length) $\times 1.2 \mathrm{~m} \quad$ (height) $\times 0.3 \mathrm{~m}$ (width). The model test should satisfy the following conditions: geometric similarity, kinematic similarity, dynamic

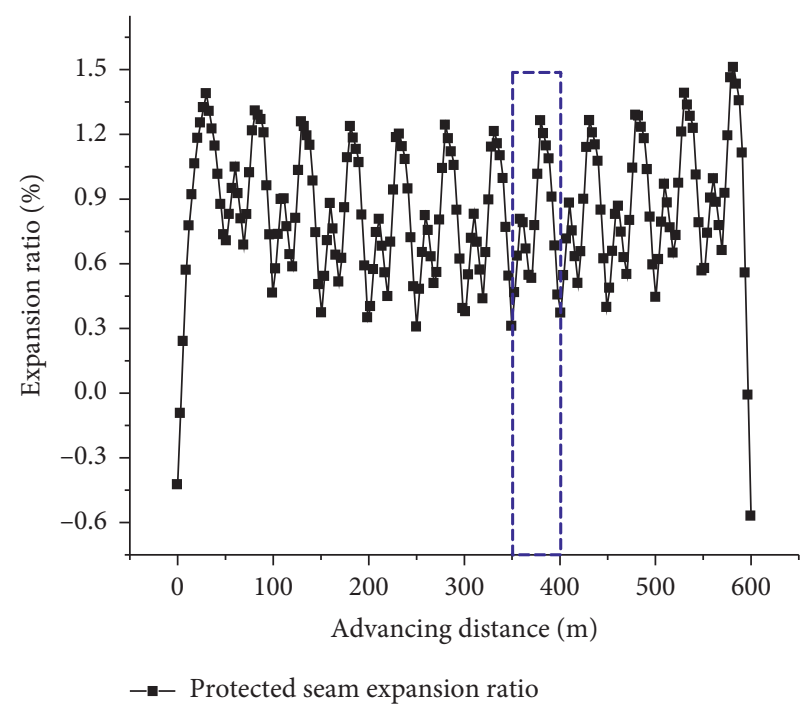

FIGURE 18: Change curve of protected expansion rate.

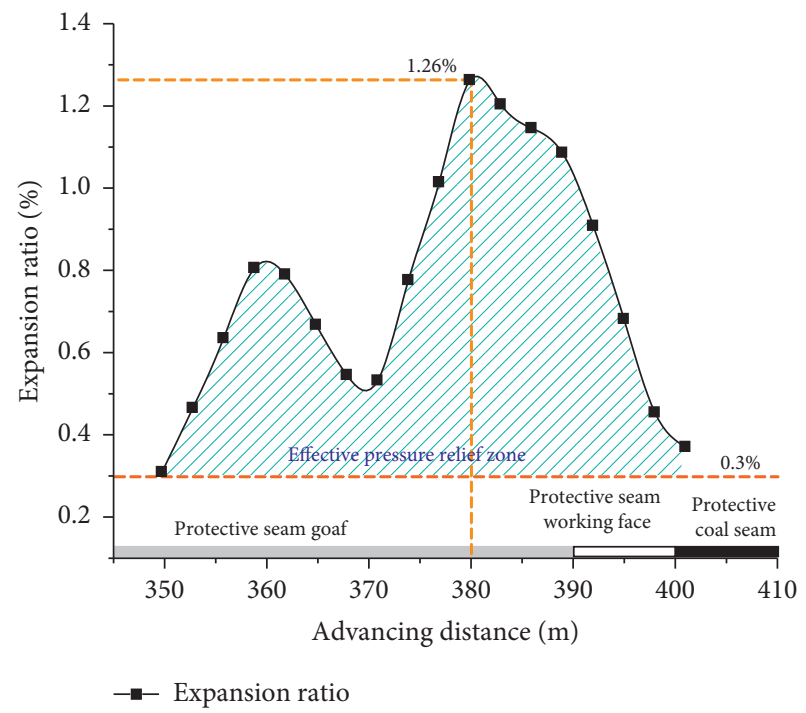

FIgURE 19: The curve of the average expansion range of $350 \mathrm{~m} \sim 400 \mathrm{~m}$ intercepted by the protected layer.

similarity, similarity of boundary conditions, and proportionating physical quantities. Therefore, the linear ratio was taken as $1: 100$, volume weight ratio was $3: 5$, and time ratio was $1: 12$. The ratio table of the main layers of the experimental model is shown in Table 5. The model and the distribution of measuring points are shown in Figures 20 and 21 .

Strain gauges were laid on the protected seam and deformation monitoring points were arranged to perform realtime monitoring of 8 \# coal pressure and deformation of coal and rock mass. A total of 8 strain gauges are arranged in the horizontal direction, the middle $2 \#-7 \#$ strain gauges are spaced $30 \mathrm{~cm}$ apart, and the two ends of the strain gauges $1 \#$ and $8 \#$ are spaced $30 \mathrm{~cm}$ apart from the end of the steel 
TABLE 5: Experimental model ratio.

\begin{tabular}{|c|c|c|c|c|c|c|}
\hline Lithology & Thickness $(\mathrm{cm})$ & Matching number (sand: lime: plaster) & Sand $(\mathrm{kg})$ & Lime $(\mathrm{kg})$ & Plaster $(\mathrm{kg})$ & Water $(\mathrm{kg})$ \\
\hline Sandy mudstone & 16.5 & $9: 0.5: 0.5$ & 200.48 & 11.14 & 11.14 & 22.75 \\
\hline Siltstone & 8.0 & $8: 0.6: 0.4$ & 96.0 & 7.2 & 4.8 & 10.8 \\
\hline Mudstone & 0.5 & $8: 0.6: 0.4$ & 6.0 & 0.45 & 0.3 & 0.7 \\
\hline Quartz sandstone & 7.6 & $7: 0.5: 0.5$ & 89.8 & 6.4 & 6.4 & 10.3 \\
\hline $9-2 \#$ coal & 0.9 & $8: 0.7: 0.3$ & 10.8 & 0.95 & 0.41 & 1.2 \\
\hline Mudstone & 1.8 & $8: 0.6: 0.4$ & 21.6 & 1.62 & 1.08 & 2.4 \\
\hline $9-1 \#$ coal & 1.9 & $8: 0.7: 0.3$ & 22.8 & 2.0 & 0.86 & 2.6 \\
\hline Mudstone & 2.5 & $8: 0.6: 0.4$ & 30.0 & 2.25 & 1.5 & 3.4 \\
\hline Siltstone & 5.2 & $8: 0.6: 0.4$ & 62.4 & 4.68 & 3.12 & 7.0 \\
\hline Sandy mudstone & 1.3 & $9: 0.5: 0.5$ & 15.8 & 0.88 & 0.88 & 1.8 \\
\hline 8\# coal & 3.6 & $8: 0.7: 0.3$ & 43.2 & 3.78 & 1.62 & 4.9 \\
\hline
\end{tabular}

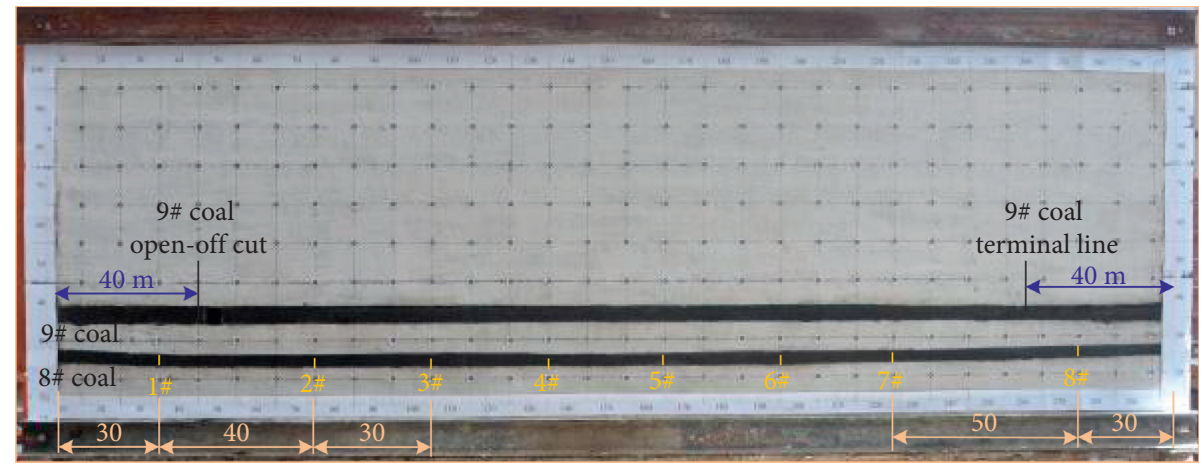

FIGURE 20: Unexcavated model diagram of similar simulation test.

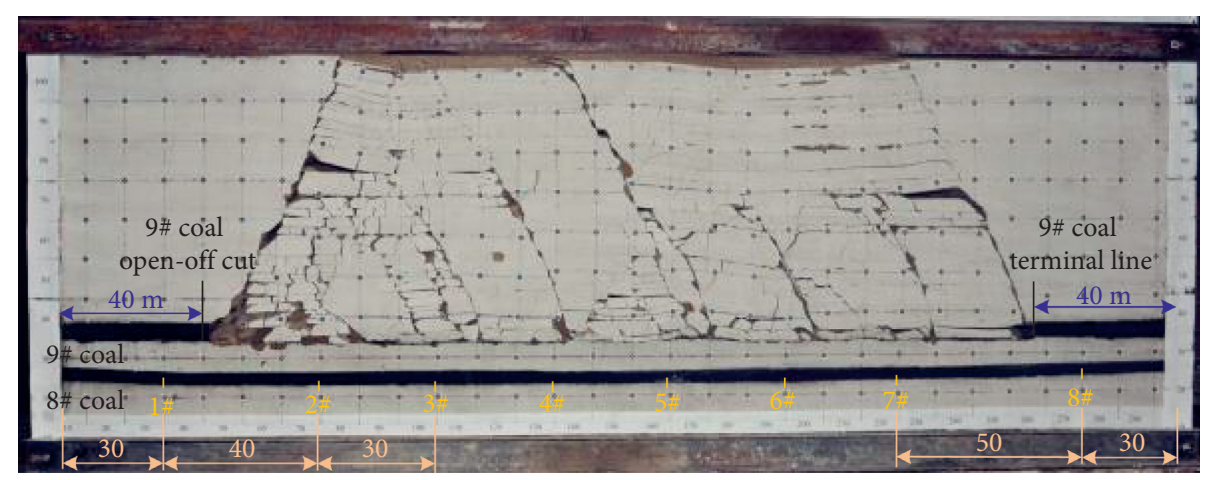

FIgURe 21: Model diagram after excavation of similar simulation test.

frame. The strain change curves at measuring points $1 \#-8 \#$ are shown in Figures 22 and 23.

As shown in Figures 22 and 23, the protective seam mining resulted in the stress relief of the underlying protected seam, and the roof and floor of the protected seam experienced upward swelling deformation. As the working face was advanced from the open-off cut to $40 \mathrm{~m}$ before the mining stopping line, the maximum roof and floor displacements were 0.267 and $0.216 \mathrm{~m}$, respectively. The maximum expansion ratio $(1.32 \%)$ was reached at $14.5 \mathrm{~m}$ behind the coal wall. The effective pressure relief zone was from the coal wall to $47 \mathrm{~m}$ behind the coal wall, which was approximate to the theoretical analysis and numerical simulation results.
5.4. Guidance and Suggestions for the Gas Extraction Design Scheme of Underlying Protected Seam. The 9\# coal was close to the underlying $8 \#$ coal seam, and pressure relief gas of $8 \#$ coal ( $8 \#$ coal gas pressure was $1.52 \mathrm{MPa}$, and gas content was $5.5 \mathrm{~m}^{3} / \mathrm{t}$ ) would surge into the goaf of $9 \#$ coal working face during the mining period of $9 \#$ coal working face. The extraction and drainage were simultaneously implemented in the upper protective seam mining, drilling was done toward upper strata in the floor roadway in the form of meshes, and the gas drainage of $8 \#$ coal seam was conducted within the effective pressure relief zone. Thus, the gas in the pressure relief zone was effectively prevented from permeating into the upper goaf, and the safe and efficient mining of the working face could be guaranteed. 


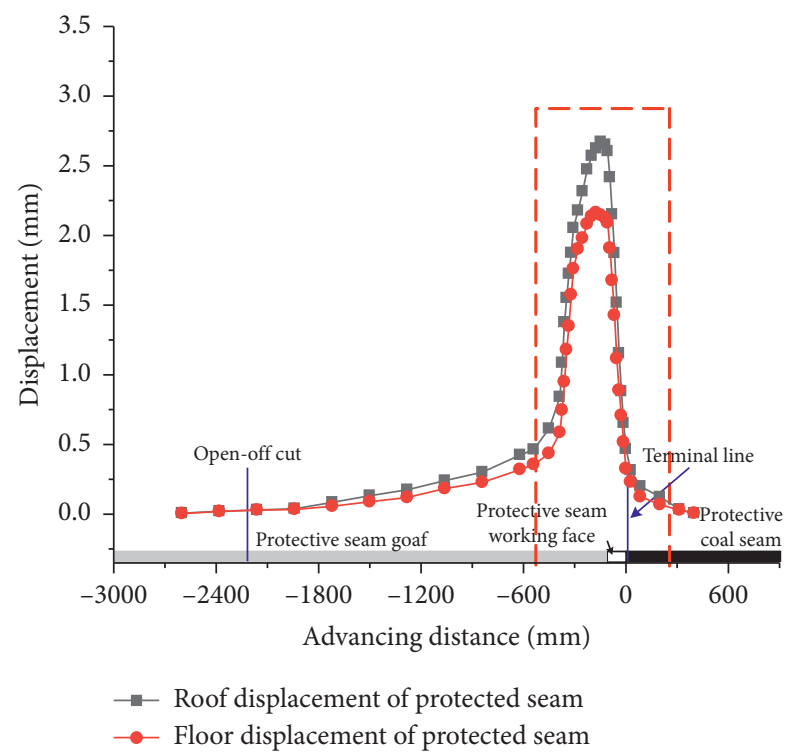

Figure 22: Displacement curve of the top and bottom plates of the protected layer.

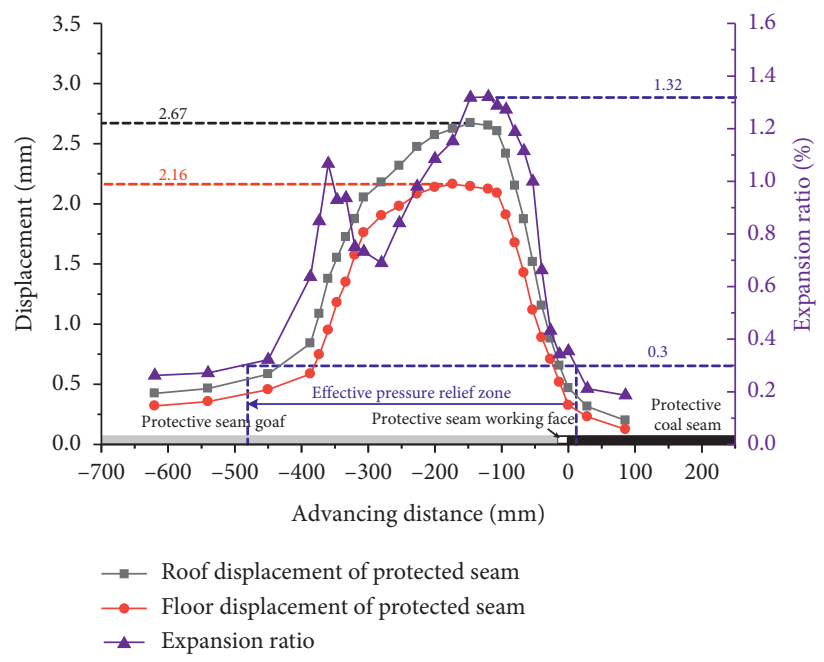

FIGURE 23: Change curve of protective layer expansion rate.

\section{Conclusions}

(1) A mechanical model was constructed for the pressure relief protection effect of upper protective seam mining on the coal and rock mass between underlying beds. The equation for the expansion ratio distribution of underlying protected seam was also acquired. The pressure relief evolution laws of the protected seam before and after mining were further analyzed and verified through numerical simulation and similarity simulation test. The theoretical results are basically consistent with the numerical simulation results. The expansion rates are $1.25 \%$ and $1.268 \%$, respectively, and the physical experimental results are $1.32 \%$. The major reason for the results may be man-made reasons in the process of model making and mining.
(2) The effective pressure relief zone of the protected seam was located within the range from the coal wall to nearly $40 \mathrm{~m}$ behind it, and it presented an approximate " $\Lambda$-shaped distribution." With the advancement, migration, and evolution of the working face, the peak pressure relief lagged behind the coal wall by around $10-20 \mathrm{~m}$. The numerically simulated expansion ratio in the goaf also presented an approximate " $\Lambda$-shaped distribution." The effective pressure relief zone was from the coal wall to approximately $50 \mathrm{~m}$ behind the goaf, and the peak value lagged behind the coal wall of the working face by around $15 \mathrm{~m}$.

(3) The elastic modulus $E$ of coal seam and interbed spacing $\mathrm{H}$ were the main influencing factors of the swelling deformation, and they were negatively 
correlated with the expansion ratio. Meanwhile, the influence of coal seam thickness on the overall selling deformation could be neglected. The interbed spacing was one of the primary influencing factors of the stress change of the protected seam. The change in the stress concentration coefficient $k$ had an obvious effect on bearing the pressure of the coal and rock mass in front of the coal wall. However, it had no obvious pressure relief effect on the underlying protected seam in the rear goaf.

(4) The expansion ratio and expansion zone of the protected seam were mastered in a real-time way, and the pressure relief degree and its scope of influence were reflected. With the advancement in the working face of protective layer, the peak expansion ratio in the goaf was also followed up timely. A good pressure relief zone was also provided for the gas extraction from the highly gassy coal seam. This study provides a theoretical reference for the decision making in the gas extraction engineering design and pre-evaluation of extraction effect.

\section{Data Availability}

The data generated or analyzed during this study are included within this article.

\section{Conflicts of Interest}

The authors declare that they have no conflicts of interest.

\section{Authors' Contributions}

Jiaxin Dang and Qingwei Bu conducted theoretical calculation and analysis; Jiaxin Dang, Min Tu and Xiangyang Zhang conducted field data collection; Jiaxin Dang and Qingwei Bu conducted numerical simulation analysis; Jiaxin Dang wrote the manuscript.

\section{Acknowledgments}

This study was supported by the NSFC Project (52074008), Anhui Collaborative University Innovation Project (GXXT2020-056), Inner Mongolia Natural Science Foundation Project (2019MS05055), and Open Research Fund Project of Key Laboratory of Safety and High-Efficiency Coal Mining of Ministry of Education (JYBSYS2019208).

\section{References}

[1] M. B. Díaz Aguado and C. González Nicieza, "Control and prevention of gas outbursts in coal mines, Riosa-Olloniego coalfield, Spain," International Journal of Coal Geology, vol. 69, no. 4, pp. 253-266, 2007.

[2] K. Noack, "Control of gas emissions in underground coal mines," International Journal of Coal Geology, vol. 35, no. 1-4, pp. 57-82, 1998.

[3] S. Zhenqi, L. Yixue, and C. Mengbo, "Discussion on the manifestation of abutment pressure before and after rock beam fracture and its application," Shandong Mining Institute Journal, vol. 1, no. 1, pp. 27-39, 1984.
[4] R. M. Flores, "Coalbed methane: from hazard to resource," International Journal of Coal Geology, vol. 35, no. 1, pp. 3-26, 1998.

[5] Z. Cao, X. He, E. Wang, and B. Kong, "Protection scope and gas extraction of the low-protective layer in a thin coal seam: lessons from the DaHe coalfield, China," Geosciences Journal, vol. 22, no. 3, pp. 487-499, 2018, https://www.infona.pl/resource/ bwmeta1.element.springer-000000012303/tab/jContent/facet? field $=\% 5$ ejournalYear\%5ejournalVolume\&value $=\% 5$ e_02018\% 5e_00022.

[6] W. Wang, Y. P. Cheng, and L. Yuan, "Floor fracture evolution and relief gas drainage timeliness in deeper underground short-distance upper protective coal seam extraction," Journal of China Coal Society, vol. 41, no. 3, 2016.

[7] W. Ren, H. Zhou, D. Xue, and L. Wang, "Mechanical behavior and permeability of coal and rock under strong mining disturbance in protected coal seam mining," Meitan Xuebao/ Journal of the China Coal Society, vol. 44, no. 5, pp. 1473-1481, 2019.

[8] D. J. Xue, H. W. Zhou, L. Kong, T. Zhao, H. Yi, and X. L. Tang, "Mechanism of unloading-induced permeability increment of protected coal seam under mining," Yantu Gongcheng Xuebao/Chinese Journal of Geotechnical Engineering, vol. 34, no. 10, pp. 1910-1916, 2012.

[9] H. F. Wang, Y. P. Cheng, D. M. Wu, and H. Y. Liu, "Gas emission and parameter optimization of gas extraction in mining face of short distance protective seam," Journal of China Coal Society, vol. 35, no. 4, pp. 590-594, 2010.

[10] M. Zhang, H. Shimada, T. Sasaoka, K. Matsui, and L. Dou, "Evolution and effect of the stress concentration and rock failure in the deep multi-seam coal mining," Environmental Earth Sciences, vol. 72, no. 3, pp. 629-643, 2014.

[11] D. Zhang, X. Qi, G. Yin, and B. Zheng, "Coal and rock fissure evolution and distribution characteristics of multi-seam mining," International Journal of Mining Science and Technology, vol. 23, no. 6, pp. 835-840, 2013.

[12] W. Cheng, Z. Nong, L. Guichen, and Z. Nianchao, "Destressed mining of multi-seams: surrounding rock control during the mining of a roadway in the overlying protected seam," Mining Science and Technology, vol. 21, no. 2, pp. 159-164, 2011.

[13] H. P. Xie, H. W. Zhou, D. J. Xue, and P. Peak, "Theory, technology and engineering of simultaneous exploitation of coal and gas in China," Journal of China Coal Society, vol. 39, no. 8, pp. 1391-1397, 2014.

[14] Y. Liu, F. Zhou, J. Wang, and J. Liu, “Approach to increasing the quality of pressure-relieved gas drained from protected coal seam using surface borehole and its industrial application," International Journal of Coal Science \& Technology, vol. 2, no. 1, pp. 46-51, 2015.

[15] P. Lu, P. Li, J. Chen, C. Zhang, J. Xue, and T. Yu, "Gas drainage from different mine areas: optimal placement of drainage systems for deep coal seams with high gas emissions," International Journal of Coal Science \& Technology, vol. 2, no. 1, pp. 84-90, 2015.

[16] H. Wang, Study on the Strata Behavior Characteristics of Fully Mechanized Caving under the Goaf of Continuous Seam Group, p. 14, Liaoning Technical University, Fuxin, China, 2016.

[17] F. K. Xiao, L. Q. Duan, and Z. H. Ge, "Laws of floor breaking in coal mining face and gas extraction application," Journal of China Coal Society, vol. 35, no. 3, pp. 417-419, 2010.

[18] M. Xiangrui, X. Chenghui, G. Zhaoning, G. Zhaoning, and W. Xiangqian, "Stress distribution and damage mechanism of 
mining floor," Journal of China Coal Society, vol. 35, no. 11, pp. 1832-1836, 2010.

[19] H. Zhang, Study on Stress Transmission Laws of Mining Floor and its Influence on Stability of Floor Roadway, pp. 11-14, China University of Mining and Technology, Xuzhou, China, 2011.

[20] F. Qi, Study on the Deformation Mechanism and Control of Surrounding Rock with Roof Cutting and Pressure Re-leasing in High Stress Roadway Driving along Next Goaf, China University of Mining and Technology, Xuzhou, China, pp. 73-74, 2020.

[21] M. Shabanimashcool and C. C. Li, "Numerical modelling of longwall mining and stability analysis of the gates in a coal mine," International Journal of Rock Mechanics and Mining Sciences, vol. 51, pp. 24-34, 2012.

[22] D. N. Whittles, I. S. Lowndes, S. W. Kingman, C. Yates, and S. Jobling, "Influence of geotechnical factors on gas flow experienced in a UK longwall coal mine panel," International Journal of Rock Mechanics and Mining Sciences, vol. 43, no. 3, pp. 369-387, 2006.

[23] Z. Zhang, J. Bai, Y. Chen, and S. Yan, "An innovative approach for gob-side entry retaining in highly gassy fullymechanized longwall top-coal caving," International Journal of Rock Mechanics and Mining Sciences, vol. 80, pp. 1-11, 2015.

[24] H. Yavuz, "An estimation method for cover pressure re-establishment distance and pressure distribution in the goaf of longwall coal mines," International Journal of Rock Mechanics and Mining Sciences, vol. 41, no. 2, pp. 193-205, 2004.

[25] L. R. Alejano and E. Alonso, "Considerations of the dilatancy angle in rocks and rock masses," International Journal of Rock Mechanics and Mining Sciences, vol. 42, no. 4, pp. 481-507, 2005.

[26] W. Li, J. Bai, S. Peng, X. Wang, and Y. Xu, "Numerical modeling for yield pillar design: a case study," Rock Mechanics and Rock Engineering, vol. 48, no. 1, pp. 305-318, 2015.

[27] B. G. D. Smart and S. M. Haley, "Further development of the roof strata tilt concept for pack design and the estimation of stress development in a caved waste," Mining Science and Technology, vol. 5, no. 2, pp. 121-130, 1987. 